Am ausgesprochensten sind aber die Lungenveränderungen infolge von bronchopneumonischen Infiltrationen mit starken Hämorrhagien., durch die die Lungen von intensiv infizierten Versuchstieren nach ca. 5 Tagen über und über ein so dunkelrotes Aussehen annehmen können, als ob sie.ein Klumpen geronnenes Blut wären, und die, wie erwähnt, auch zum Tode führen. Nach STEwarT und nach Ransom und seinen Mitarbeitern gehen Ferkel aber offenbar auch unter natürlichen Bedingungen häufig an Ascaridenpneumonie zugrunde; aber der Mensch wird ja, wie oben schon bemerkt, kaum jemals annähernd so große Mengen von Ascariseiern auifnehmen, wie die im Kote wühlenden Ferket. Immerhin sind nach experimenteller Ascariseierverfütterung auch bei Menschen Bronchitiden beschrieben worden ${ }^{7}$ ): Nur wäre es natürlich völlig unberechtigt, z. B. bei einem Kinde, bei dem man erwachsene Ascaris im Darme feststellt, eine gleichzeitig vorhandene Bronchitis nun ohne weiteres etwa damit in Zusammenhang bringen zu wollen, da die Wanderung der Larven der Ausreifung der Würmer ja monatelang vorausgeht, und dasselbe gilt natürlich von Gehirnsymptomen usw. Ob Ascariden infolge von Toxinen z. B. Lungen- und Gehirnerscheinungen verursachen könnten, ist natürlich eine ganz andere Frage.

Andererseits ist zu bemerken, daß sehr. wohl Symptome durch wandernde Ascaridenlarven auftreten könnten, ohne

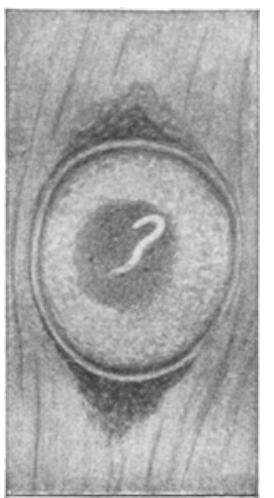

ADD. 6. Belascariscysten aus dem Heramusket eintes frischem Material $40: I$. daß jemals später ausgereifte Würmer im Darme festgestellt werden, da (wie wir aus den Tierexperimenten wissen), infolge von erworbener Immunität $z$. B., sicher keineswegs immer die in dem Körper wandernden Ascarislarven später auch zur Geschlechtsreife heranwachsen. Ferner könnten auch für den Menschen ,artfremde" Ascarislarven, z. B. Belascaris des Hundes, wohl ebenso wie bei meinen Mäusen und Meerschweinchen, auch im Menschen wandern, was speziell bei Belascaris insofern von besonderem Interesse ist, als bei diesem Parasiten die lebenden Larven in Niere, Leber, Muskeln und anderen Organen, ähnlich wie Trichinen, eingekapselt werden könnèn, was bei Ascaris lumbricoides höchstens ausnahmsweise der Fall sein mag. Diese Belascariscysten sind auch bei spontan infizierten Hunden sie wurden in anderem Zusammenhang aus der Hundeniere bereits erwähnt - manchmal recht reichlich vorhanden; freilich sind - trotz der Verstreuung der Eier dieses überaus häufigen Hundeparasiten in unseren Straßen - solche Belascarisknötchen bei Menschen bisher nicht bekannt geworden. Nur biologische nicht praktische Bedeutung hat es, daß, wie ich nachweisen konnte ${ }^{2}$ ), Verfütterung dieser Cysten bei Hunden zur Darminfektion führt. Ebenso hat es sicherlich keine praktische Bedeutung, daß Ascariden durch den Speichel - z. B. beim $\mathrm{KuB}$ - von Mensch zu Mensch übertragen werden könnten, wenn schon das mindestens nicht weniger Wahrscheinlichkeit haben đürfte wie die oben erwähnte Thec:- : der Übertragung durch Rattenspeichel, die STEWART aufgestellt hat.

\section{ÜBER DAS VORKOMMEN VON GALLENSÄUREN BEIM IKTERUS UND DEN IKTERUS DISSOCIATUS.}

Von

Dr. HAROLD BORCHARDT.

Aus der I. Inneren Abteilung des Städt. Krankenhauses Charlottenburg-Westend. (Direktor: Professor Dr. UMBER.)

Ikterus kommt bekanntlich zustande durch Gallenfarbstoffretention im Organismus. Man unterscheidet zwei Hauptformen: den mechanischen Stauungsikterus und den hämolytischen Ikterus. Im allgemeinen werden beim Ikterus

1) MOSLER bei LEUCKART 1. c.; LUTZ, Zentralbl. f. Bakteriol, I888, S. 425.

2) FULLEBORN, 1. C. Ig2I, S. $367(1 / \mathrm{s}) \mathrm{ff}$. neben den Gallenfarbstoffen auch die Gallensäuren retiniert. Die retinierten Gallenstoffe eliminiert der Körper hauptsächlich durch die Nieren; daneben kommt es zuweilen auch vor, daß Bilirubin im. Schweiß, ja, selbst in der Tränenflüssigkeit auftritt.

In neuerer Zeit wurde von verschiedenen Seiten, insbesondere von französischen Autoren (LIT, CHAUFFard, LAROche, Grigaut, Brulé, Garban, Lemierre u. a.) berichtet, daß bei vielen Fällen von Ikterus in der Retention der Gallenstoffe eine Dissoziierung eintrete. Hauptsächlich seien es die Rekonvaleszenzperioden, die in der Regel eine Dissoziierung erkennen ließen. Man nannte entsprechenderweise diese Ikterusform: Ikterus dissociatus.

Das Vorkommen dieses Ikterus dissociatus wurde als Beweis dafür aufgestellt, da $\beta$ der Ikterus kein mechanischer sein könne. Es soll nun hier auf Veranlassung von Prof. UMBER untersucht werden, ob das Vorkommen des Ikterus dissociatus tatsächlich ein so häufiges ist, wie die französischen Autoren angeben, oder ob nicht vielleicht diese durch irgendwelche Mängel der Untersuchungsmethoden, die Häufigkeit des Ikterus dissociatus überschätzt haben.

Es ist in der Bezeichnung: Ikterus dissociatus zum Ausdruck gebracht, daß die Gallensäuren im Blut und Harn fehlen; denn die Gallenfarbstoffe sind naturgemäß bei jedem Ikterus notwendig. Eine isolierte Gallensäureretention kann keine Gelbfärbung hervorrufen, hat also mit der Ikterusfrage, mit der wir uns hier beschäftigen, nichts zu tun.

Es kommt in erster Linie darauf an, einen möglichst empfindlichen Gallensäurennachweis $z u$ haben, mit dessen Hilfe alsclann Blut und Harn möglichst vieler Ikterischer, besonders in der Rekonvaleszenzzeit, zu untersuchen sind. Zugleich mit der Gallensäurenbestimmung führt man die Gallenfarbstoffbestimmungen aus, um so beide Hauptkomponenten der Gallenausscheidung in Blut und Harn nebeneinander zu háben.

Ein indirekter qualitativer Nachweis der Gallensäuren im Blut ist der von LeMIERre und Bruté angegèbene Hämoconiennachweis.

Hämoconien sind im Blutplasma suspendierte allerfeinste Fetttröpfchen, die bei ungestörter Fettresorption stets vorhanden sind und im Dunkelfeld sehr deutlich als starkglänzende kleinste Partikelchen mit Brownscher Molekularbewegung erkennbar sind. (I. F. MÜLLER, Zentralbl. f. allg. Pathol. u. pathol. Anat. 7, 529. I 896; A. NeumanN; Zentralbl. f. Physiol 2I, IO2 I007; Wiener klin. Wochenschr. I907, S. 851; A. KREIDL u. NEUMANN, Sitzungsber. d. kais. Akad. zu Wien 120, I27. I9I I; O. Weltmann, Biochem. Zeitschr. 65, 440. I9I4.; E. NEISSER u. BRAENNING, Zeitschr. f. exp. Pathol. u. Therap. 4. I907.)

Läßt man nun einen Ikterischen, der keine Gallensäuren im Darm hat, eine Fettmahlzeit (30 g Fett) zu sich nehmen, und entnimmt man dem Patienten nach zwei Stunden ein Tröpfchen Blut, so sieht man nur sehr wenig oder gar keine Hämoconien (Lemrerre und Brulé, Brulé und Garban im Traité de Pathologie médicale. Vol. XII. Paris I920. BRULÉ in seinen Recherches récentes sur les Ictêres).

Ich konnte diese von LEMIERRE und Brule konstatierte Tatsache des Fehlens von Hämoconien an einigen Ikterusfällen unserer Abteilung bestätigen. Es ist daher möglich, daß dieser Hämoconiennachweis bei der Diagnose des hämolytischen Ikterus, bei dem ebenso wie beim normalen Menschen eine Vermehrung derselben nach Fettgenuß auftreten maß, von Wert ist. Jedoch ist diese Methode eine sehr grobe qualitative und vor allem eine indirekte, die für alle Störungen der Fettresorption gilt. Viel wesentlicher ist es daher, die Gallensäuren selbst direkt in einer Weise nachzuweisen, die uns Rückschlüsse auf ihre Quantität erlaubt.

Die Gallensäuren haben die Eigenschaft, daß sie die Oberflächenspannung der flüssigen Medien, in denen sie sich befinden, herabsetzen, und das um so stärker, je konzentrierter die Gallensäuren auftreten. Das brachte HAY auf den Gedanken, fein verteilten Schwefel, Schwefelblume, auf die Oberfläche von Harn zu streuen. Unter normalen Verhältnissen schwimmt die Schwefelblume infolge der Oberflächenspannung des Harns auf der Oberfläche. Sind dagegen Gallensäuren im Harn, so wird infolge der Herabsetzung der Oberflächenspannung des Harns die Schwefelblume schneller 
oder langsamer zu Boden sinken. (SALM, Hays Reaktion auf Gallensäuren; Chem. Zentralbl. II, S. I I 5 I. I903.) Hauptsächlich mit dieser Methode haben die französischen Forscher nach ihren Angaben gearbeitet. Nun hat sich mir aber vielfach gezeigt, daß die Haysche Probe bereits negativ ausfiel, wenn ich noch mit der von mir benutzten viscostagonometrischen Methode geringe, aber meBbare Quantitäten von Gallensäuren nachweisen ronnte.

Auf Grund der Beobachtung, daß oft noch Pigmentausscheidung im Harne stattfand, während die Haysche Probe, die eben sehr wenig empfindlich ist, bereits negativ ausfiel, kamen die französischen Autoren, besonders Brulé, zu der Überzeugung, daß in der Rekonvaleszenzperiode des mechanischen Ikterus die Gallenstoffretention in der Regel eine dissoziierte sei. Die bereits von HAY nachgewiesene Tatsache, daß die Gallensäuren die Oberfiächenspannung der flüssigen Medien, in denen sie sich befinden, herabsetzen, führte zum viscostagonometrischen Gallensäurennachweis, dessen wir uns bei allen unseren Messungen bedient haben.

Wir benutzen das von TRAUBE angegebene Vicostagonometer. Dieses Instrument gibt bei einiger Übung der Technik recht exakte Werte und zeigt schon sehr kleine Veränderungen der Obèrflächenspannung zahlenmäßig an.

Bezüglich der technischen Einzelheiten verweise ich auf die Arbeit von Traube und Somogyi (Internat. Zeitschr. f. physik. chem. Biologie, Bd. 1., H. 5 u. 6.; ArderhaIdens Handbuch der Biochem. Arbeitsmethoden, I912; Biochem. Zeitschr. 24, $34 \mathrm{I}$. I910, U. 42, 500. I912).

$\mathrm{Da}$ es kaum zwei Viscostagonometer gibt, die genau gleichgearbeitet sind, empfiehlt es sich, die gefundene Tropiengröße auf Kubikmillimeter umzurechnen, um so übereinstimmende Vergleichswerte zu erzielen mit den verschiedenen Rohren der verschiedenen Kliniken und Laboratorien.

$Z u$ diesem $Z$ wecke braucht man nur die gefundene Tropfengröße mit dem Kubikmillimeterwert eines Teilstriches des Rohres zu multiplizieren, den man ein für allemal bestimmt hat. Die Bestimmung dieses Kubikmillimeterwertes geschieht am einfachsten so:

Man bestimmt bei der Temperatur $t^{\circ}$ die Anzahl $n$ der von einem Tropfen destillierten Wassers durchlaufenen Teilstriche. Dann bestimmt man das Gewicht $g$ eines Tropfens destillierten Wassers, bei $t^{\circ}$. Die Ausdehnung $\alpha$ von Wasser bei $t^{\circ}$ kann man in Tabellen nachschlagen.

Es besteht nun die Gleichung:

$$
\text { I Teilstrich des Viscostagonometers }=\frac{[1+\alpha t]}{n} \cdot g \mathrm{ccm} \text {. }
$$

Die Ableitung dieser Formel geschieht so:

$$
\begin{aligned}
& \mathrm{I} \operatorname{ccm} \mathrm{H}_{2} \mathrm{O} \text { bei } 4^{\circ}=\mathrm{I} g, \\
& {[\mathrm{I}+\alpha] \mathrm{ccm} \mathrm{H}_{2} \mathrm{O} \text { bei } t^{\circ}=\mathrm{I} g,} \\
& \mathrm{I} \text { Tropfen } \mathrm{H}_{2} \mathrm{O} \text { bei } t^{\circ}=g g, \\
& \frac{\mathrm{I}}{g}=\mathrm{I} \mathrm{g}=[\mathrm{I}+\alpha t] \mathrm{ccm}, \\
& \mathrm{I} \text { Tropfen bei } t^{\circ}=n \text {. Teilstriche. } \\
& \frac{\mathrm{I}}{g}=\frac{n}{g} \text { Teilstriche }
\end{aligned}
$$

oder

$$
\frac{n}{g} \text { Teilstrich }=[\mathrm{I}+\alpha t] \mathrm{ccm}
$$

oder

$$
\text { I Teilstrich }=\frac{[I+\alpha t]}{n} \cdot g \mathrm{ccm} \text {. }
$$

Die Vorteile der viscostagonometrischen Methode liegen einmal in ihrer Genauigkeit, sie gibt schon sehr geringe Veränderungen der Oberflächenspannung an, ist also der HAYschen Probe bei Harn weit überlegen. Des ferneren ist die Messung schnell in ca. I-2 Minuten ausgeführt, und sie ist gleicherweise für sämtliche Flüssigkeiten $z u$ benutzen. Da die Gallensäuren die Oberflächenspannung von Harn und Blutserum herabsetzen, so wird man sowohl im Harn als auch im Serum diese Herabsetzung viscostagonometrisch nachweisen können, und aus der Abweichung der Tropfengröße des ikterischen Harns und Serums von der des normalen Harns und Serums auf die Quantität der vorhandenen Gallensäuren schließen können.

Um für Harne brauchbare Vergleichswerte zu erzielen, empfiehlt es sich, jeden Harn, den man messen will, auf das spezifische Gewicht von Ioo7 zu bringen, da die Konzentration des Harnes die Oberflächenspannung beeinflußt. Ich habe alle meine Messungen so ausgeführt, daß ich sämtliche Harne mit Aqua destillata auf roo7 verdünnt habe und die Messungen stets im selben R $1 u m e$ bei ca. $20-22^{\circ} \mathrm{C}$ ausführte. Man nimmt am besten den Urin, der am
Morgen gelassen wird, da dieser gewöhnlich höher konzentriert ist und bei Ikterischen naturgemäß reichlich Gallensäuren enthält. Filtration des Harns empfiehlt- sich nur bei grober Verunreinigung, da durch die Filtration stets, allerdings nur gan $z$ geringe, Veränderungen der Oberflächenspannung eintreten, die sich in der 2. bis 3. Stelle nach dem Komma bewegen.

Bei der Messung von Blutseren, (man braucht ca. I-2 ccm Serum, bei fortgeschrittener Technik weniger) muB beachtet werden, daß das Serum hämoglobinfrei ist, eventuell Zentrifugieren, und daß die Messung spätestens 6-7 Stunden nach der Blutentnahme ausgeführt wird. Bei längerem Stehen des Serums ändert sich die TropfengröBe erheblich. Ob das durch bakterielle Zersetzung oder durch Ausfällung von Kolloiden bedingt ist, ist nicht festgestellt. Das Blut (Venenblut) wird am besten nüchtern entnommen, um gleiche Versuchsbedingungen zu erzielen.

Das von mir benutzte Viscostagonometer (C. GERrard, Bonn) hat 500 Teilstriche; Wasser bei $20^{\circ} \mathrm{C}$ hat bei diesem Rohr eine Tropfengröße von 25,80 Teilstrichen. Einen Teilstrich bei unserem Rohr habe ich nach der oben abgeleiteten Formel auf $4,468 \mathrm{cmm}$ berechnet.

Ich fand, daß bei normalen Harnen von roo7 spez. Gewicht bei $22^{\circ} \mathrm{C}$ die Tropfengröße schwankte zwischen Io3 $\mathrm{cmm}$ (= untere Normalgrenze) und II $2 \mathrm{cmm}(=$ obere Normalgrenze). Ging die Tropfengröße des Harnes unter ro3 cmm herunter, so war ein Vorhandensein von Gallensäuren, resp. anderen, die Oberflächenspannung herabsetzenden Substanzen, erwiesen. An über $3^{\circ}$ untersuchten normalen Harnen ging die Tropfengröße nie unter Io3 $\mathrm{cmm}$ herunter.

Daß das für den Menschen hauptsächlich in Betracht kommende glykocholsaure Natrium tatsächlich schón in minimalen Spuren Flüssigkeiten zugesetzt deren Oberflächenspannung stark herabsetzt, stellte ich an mehreren Versuchsreihen fest. Auch isolierten Gallenfarbstoff, Bilirubin; setzte ich verschiedenen Flüssigkeiten - auch normalen Hamen zu und stellte fest, daß keine Veränderung der Oberflächenspannung meßbar hervorgerufen wurde.

Es war nun noch zu prïfen, ob außer den Gallensäuren nicht noch andere Substanzen, die im Harn Ikterischer. vorkommen können, die Oberflächenspannung desselben herabsetzen. In dieser Richtung angestellte Versuche fürten zu dem Ergebnis, daß stärkere Eiweißausscheidungen; vor allem Albumosen und Peptone (vgl. TraubE), die Oberflächenspannung des Harnes verringern. Auch Schemensky (Münch. med. Wochenschr. I920, S. 773) berichtet ausführlicher hierüber.

$\mathrm{Da}$ jedoch bei Ikterus im allgemeinen eine nennenswerte Albuminurie nicht besteht, so können wir praktisch die Beeinflussung des Harns durch Eiweiß außer Betracht lassen. Es ist also wohl die Folgerung berechtigt, daß die Herabsetzung der Oberflächenspannung von Harnen Ikterischer auf der Gegenwart von Gallensäuren beruht.

Kommt es aber einmal vor, daß tatsächlich ein Ikterus mit starker Albuminurie einhergeht, so ist eben mit. dieser Methode der Nachweis der Gallensäuren im Harn nicht zu erbringen.

Bei normalen Blutseren fand ich bei Anwendung der gleichen Methode eine normale Tropfengröße, die zwischen $1 \mathrm{O}_{3} \mathrm{cmm}$ (= untere Normalgrenze) und $106 \mathrm{cmm}$ (=) obere Normalgrenze) schwankte. Die untere Normalgrenze entspricht beim normalen Serum also genau der beim normalen Harn, während die obere Normalgrenze des Harns erheblich höher liegt. Es hat sich überhaupt bei allen Messungen gezeigt, daß das Serum Ikterischer seine Oberflächenspannnng nicht so stark herabsetzen läßt, wie der Harn derselben Patienten. Das läßt darauf schließen, daß̈ das Blut die Gallensäuren nur bis $\mathrm{zu}$ einer verhältnismäßig niedrigen Konzentration duldet. Wird diese überschritten, so erfolgt gesteigerte Elimination in den Harn. Bei den Gallenfarbstoffen scheinen die Verhältnisse anders zu liegen. Das hat wohl seinen Grund darin, daß die Farbstoffretention durch den Organismus nicht von so schweren toxischen Störungen, abgesehen von der Gelbfärbung, begleitet wird, wie die Retention der Gallensäuren, wenn sie eine gewisse Konzentration überschreitet. Ich hatte Gelegenheit, einige Fälle von akuter gelber Leberatrophie zu untersuchen; da zeigte sich auch im Serum eine so starke Herabsetzung $(85 \mathrm{cmm})$. der Oberflächenspannung 
wie sonst nur in Harnen, die ja naturgemä $\beta$ im allgemeinen einen stärkeren Gehalt an Gallensäuren haben.

Im ganzen habe ich über roo Fälle von Ikterus untersucht; bei einer großen Zahl dieser Fälle wurde der Harn täglich auf Gallenfarbstoffe und Gallensäuren untersucht. Das Serum der Kranken wurde im Verlaufe der Krankheit etwa 3-4 mal mit Io-I2 tägigen Pausen untersucht, da wegen der Venenpunktion, die jedesmal vorgenommen werden mußte, ein häufigeres Blutentnehmen aus Riicksicht auf den Kranken nicht möglich war. Beim Serum wurde fast jedesmal auch die direlite HYMANS VAN DEN BERGHsche Bilirubinreaktion und einigemal auch die indirekte ausgeführt, neben der viseostagonometrischen Gallensäurenbestimmung.

Ein Fall von chronischem hämolytischen Ikterus ergab. daß sowohl im Harn als auch im Serum Gallenfarbstoffe vorhanden waren, während die Gallensäuren nicht nachweisbar waren. Dieses Ergebnis entsprach auch ganz unseren Erwartungen; denn auch klinisch fehiten alle Symptome einer Gallensäureintoxikation.

Ein zweiter Fall von perniciöser Anämie mit leichtem Ikterus ergab gleichfalls Gallenfarbstoffausscheidung ohne Gallensäurenausscheidung, also gleichfalls eine Dissoziierung. Außer diesen beiden Fällen, die zur Gruppe des hämolytischen Ikterus zu rechnen sind, habe ich niemals eine Dissoziierung bei Ikterus nachweisen können.

Im Gegenteil zeigte sich bei allen anderen untersuchten Fällen regelmäßig ein Parallelismus im Auftreten der Gallenfarbstoffe und Gallensäuren im Harn resp. Serum sowie bei abklingendem Ikterus eine parallele Verminderung und schließliches gleichzeitiges Verschwinden der Gallenstoffe aus Harn resp. Serum. Insgesamt wurden untersucht 29 Fälle von infektiöser Cholangie, I I Fälle von Cholelithiasis, 4 Lebercirrhosen, I chronisch-hämolytischer Ikterus, I perniciöse Anämie mit Ikterus, 2 Fälle von Typhus abd. mit Subikterus, 9 Salvarsanschädigungen, 8 Pneumonien mit Ikterus resp. Subikterus, I9 Fälle von Ikterus catarrhalis, 3 akute, resp. subakute gelbe Leberatrophien, 8 Lebermetastasen bei $\mathrm{Ca}$ in abdomine, 3 Fälle von Leberlues, 2 Fälle von Stauungsleber, $x$ Fall von Lungentuberkulose mit Ikterus, 2 Polycythämien (I VAQUEzsche Form und I GeIssBöcksche Form), - ohne Ikterus und ohne Gallenstoffausscheidung, die beide eine normale Oberflächenspannung im Harn und Serum zeigten, - I Fall von Appendicitis mit normalen Verhältnissen, 5 Fälle von Typhus abd. ohne Ikterus mit normalen Verhältnissen, 3 Fälle von Nierenschädigungen mit starker Albuminurie, bei denen sich keine Gallenfarbstoffausscheidung, aber eine starke Herabsetzung der Oberflächenspannung des Harnes fand, die durch die Albuminurie erklärt war; I Fall von Skorbut, I paroxysmale Hämoglobinurie, 8 Magendarmerkrankungen, 3 Herzerkrankungen, I essentielle Hypertonie, I multiple Sklerose, 3 Diabetes, die gleichfalls alle normale Verhältnisse zeigten.

Bei den Fällen, bei denen der Ikterus sehr intensiv war und bei denen das Urobilin und Urobilinogen im Harn bei starker Bilirubinurie völlig fehlten, war die Oberflächenspannung im Harn und Serum ebenfalls stark verringert; es fanden sich da durchschnittlich Tropfengrößen zwischen 80 und $90 \mathrm{cmm}$ im Harn, im Serumi um go $\mathrm{cmm}$. Stärkere Verringerungen im Serum fanden sich ausschließlich bei akuter bzw. subakuter gelber Leberatrophie. Sobald dagegen Urobilinogen und Urobilin im Harn auftraten und die Bilirubinurie schwächer wurde, stieg die Tropfengröße auf über $90 \mathrm{cmm}$, um sich langsam parallel mit der Abnahme der Farbstoffausscheidung der Normalzahl Io3 $\mathrm{cmm}$ zu nähern, die jedesmal mit dem völligen Schwinden der pathologischen Farbstoffausscheidung erreicht wurde. Es fand sich đabei regelmäßig, daß die HAY sche Probe bereits bei einer Tropfengröße von $100 \mathrm{cmm}$, bei der stets noch Farbstoffausscheidung statt hatte, negativ ausfiel. Hieraus erhellt fraglos, daß die Haysche Probe zu unempfindlich ist und bei geringer Gallensäureausscheidung absolut versagt.

$\mathrm{Da}$ ich hier wegen Raummangels nicht mein ganzes tabellarisch zusammengestelltes Beweismaterial veröffentlichen kann, führe ich nur einige Fälle an. (Die ausführlichen
Tabellen, die roo Fälle umfassen, finden sich in meiner Dissertation, Berlin, März 1922.)

Fall von Ikterus catarrhalis:

Am I. Tag der Untersuchung zeigte sich bei stärkerem Ikterus Bilirubinurie, Tropfengröße von $94 \mathrm{cmm}$ im Harn, Bilirubin im Serum (direkt nach Hymans v. D. BeRGH) +++ , Tropfengröße im Serum $96 \mathrm{cmm}$.

Im Laufe der folgenden Tage nahm der Ikterus zu, die Bilirubinurie wurde intensiver, die Harntropfengröße fiel auf $92 \mathrm{cmm}$, die Serumtropfengröße fiel auf $94 \mathrm{cmm}$ bei Bil. dir. ++++ , die Haysche Probe war positiv. Nach weiteren io Tagen nahm der Ikterus ab, Bilirubin im Harne schwand, es traten Urobilin und Urobilinogen auf, die Harntropfengröße stieg auf $97 \mathrm{cmm}$, die Serumtropfengröße wurde normal bei negativem direkten Bilirubin, die Hay sche Probe war schwach positiv. Am folgenden Tage war die Harntropfengröße auf $100 \mathrm{cmm}$ angestiegen bei schwächerer Farbstoffausscheidung und negativer Hayscher Probe; nach weiteren 2 Tagen war die Farbstoffausscheidung geschwunden und die normale Harntropfengröße von $103 \mathrm{cmm}$ erreicht.

Fall von hämolytischem Ikterus:

Im Serum, bei mehrfachen Untersuchungen, direktes Bilirubin negativ, indirektes schwankte zwischen I : 43000 und I : 25000 , Tropfengröße von I04-I05 cmm. Im Harn: fortgesetzte Ausscheidung von Urobilin und Urobilinogen bei stets normaler Tropfengröße von $103-106 \mathrm{cmm}$ und stets negativer HaYscher Probe.

Fall von subakuter gelber Leberatrophie:

Im Serum: Direktes Bilirubin stark positiv $(t+t+)$, Tropfengröße $87 \mathrm{cmm}$.

Im Harn: Fehlen von Urobilin und Urobilinogen, starke Bilirubinurie, Tropfengröße $86 \mathrm{cmm}$. Unter zunehmendem Ikterus und zunehmender Benommenheit stärkerwerdende Bilirubinurie und Abfall der Harntropfengröße auf $83 \mathrm{cmm}$. Am nächsten Tage Exitus.

Fall von Cholangie:

Im Serum: Bilirubin direkt ++ , Tropfengröße $94 \mathrm{cmm}$.

Im Harn: Fehlen von Urobilin und Urobilinogen, Tropfengröße von $88 \mathrm{cmm}$, starke Bilirubinurie.

Der Harnbefund hielt sich mit geringen Schwankungen der Tropfengröße annähernd 4 Wochen unverändert, dann wurde die Bilirubinurie schwächer, Urobilin und Urobilinogen traten àf, die Tropfengröße stieg auf $99 \mathrm{cmm}$ bei negativer HA y scher Probe, am folgenden Tage wurde bei Fehlen von pathologischer Farbstoffausscheidung eine normale Tropfengröße von $107 \mathrm{cmm}$ erreicht.

Es sind zwar die von mir untersuchten Fälle ein geringeres Zahlenmaterial, als es die französischen Untersucher angeben; doch ist zu berücksichtigen, daß systematisch jeder Fall von Ikterus, der in unsere Abteilung eingeliefert wurde, untersucht worden ist, daß nicht etwa nur stark ikterische Patienten oder überhaupt nur ausgewählte Fälle untersucht wurden. Ich glaube auf Grund meiner Untersuchungen aussprechen zu dürfen, daß die französischen Forscher, da sie fast ausschließlich die $\mathrm{H}_{\mathrm{AY}}$ sche Probe zum Nachweis der Gallensäuren anwandten, oft eine Gallensäurenausscheidung nicht feststellten und auch mit der Hayschen Probe nicht feststellen konnten. Es wäre sicherlich wohl in vielen ihrer Fälle mit Hilfe des Viscostagonometers noch eine Gallensäurenausscheidung bei negativer Hayscher Probe festzustellen gewesen, wie ich es relativ häufig bei den von mir untersuchten Fällen fand.

Zusammenfassend ergibt sich:

I. Nur der dynamische Ikterus hämolyticus ist dissoziiert.

2. Der mechanische Ikterus ist nie dissoziiert.

3. Somit fällt auch das Argument der französischen Autoren gegen die mechanische Auffassung dieser Form.

Literatur: I. ABDERHALdEns Handbuch der Biochemischen Arbeitsmethoden. I9I2. - 2. Biochem. Zeitschr. 24, 34I. I 9 IO U. 42, 500. I9I2. - 3. BRULE, Recherches récentes sur les Ictères. Paris 1920. - 4. Dtsch. med. Wochenschr. I92I, H. 27 , 28, 30, 31. Aussprache über Ikterus in der Berliner Medizinischen Gesellschaft, - 5. Garban u. BRult, Traité de Pathologie medicale, Vol. XII. Paris 1920. - 6. KReIdL u. Neumann, Sitzungsber. d. kais. Akad. zu Wien I20, I27. IgII. - 7. MÜLLER, Zentralbl. f. allg. Pathol u. pathol. Anat. 7, 529. I 896. - 8. NeISSER u. BRäUNIG, Zeitschr. f. exp. Pathol, u. Therap. 4. I907. - 9. NEUBERG u. Rauchwerger, Chem. Zentralbl. II, S. I434/35. I904. io. Neumann, Zentralbl. f. Physiol. 2i, IO2. I907. - ir. PRegL, 
Chem. Zentralbl. II, S. 517. I905. - I2. SALM, Hays Realktion auf Gallensäuren, Chem. Zentralbl. II, S. II5I. 1903. - I3. ScheMENSKy, Münch. med. Wochenschr. 1920, S. 773. - I4. Traube u. Somogyi, Internat. Zeitschr. f. physik.-chem. Biol. Bd. I, 5. u. 6. Heft. - I5. Traube u. Blumenthal, Zeitschr. f. exp. Pathol. u. Therap. 2, II7/118. 1905. - I6. WeltMANn, Biochem. Zeitschr. 65, 440. I9I4. - I7. Wiener klin. Wochenschr. 85 I. I907.

\section{VÖLLIGER ABRISS EINES PAPILLARMUSKELS IM LINKEN VENTRIKEL DURCH CORONAR- SKLEROSE.}

\section{Von}

Prof. Bernh. Fischer,

Direktor des Senckenbergischen Pathologisch. Instituts der Univ. Frankfurt a. M.

Durch stumpfe Gewalteinwirkungen, insbesondere Quetschungen des Thorax können, wie eine Reihe von Beobachtungen am Menschen und in voller Übereinstimmung damit Tierversuche gezeigt haben ${ }^{1}$, , auch Verletzungen der Innenteile des Herzens, insbesondere Klappenbasisblutungen ent stehen. Direkte Zerreißungen, insbesondere Abreißen von Klappenteilen oder gar Papillarmuskeln, entstehen jedoch nur sehr seiten und wohl ausschließlich bei sehr schweren Verletzungen. Daß bei der Zerquetschung des Herzens zwischen Eisenbahnpuffern (sogar ohne Zertrümmerung des Brustkorbes ${ }^{2}$ ), da $B$ bei den furchtbaren Zerreißungen des Herzens durch Fliegerabsturz auch Abreißen des Papillarmuskels - BERBLINGER bildet einen solchen Fall ab - vor kommen kann, ist klar.

In der Literatur sind auch mehrfach Mitteilungen darüber gemacht worden, daß Herzklappen bei ungewöhnlich starken Muskelanstrengungen zerreißen können. Schon Rokitansky meinte $\mathrm{da} \beta$ in diesen Fällen stets eine entzündliche Veränderung der Klappen vorgelegen habe. Es ist klar, daß bei entzündlichen Veränderungen der Klappen und Sehnenfäden, besonders maligner Endokarditis, eine starke Muskelanstrengung leicht zum Zerreißen führen kann (DUNBAR ${ }^{3}$ ); doch sind auch Fälle beschrieben worden, wo bei angeblich völlig unveränderten Klappen durch stärkste Muskelanstrengungen, z. B. rasches Bücken (siehe bei FRAEnTZEL ${ }^{4}$ ), solche Zerreißungen eintraten LiNDMAN ${ }^{5}$ ).

All dies liegt in dem Falle, den ich im folgenden beschreibe, nicht vor, sondern hier ist es ohne jede besondere körperliche Anstrengung und ohne da $B$ auch nur das leichteste Trauma vorausgegangen ist, zu einem spontanen Abreißen eines ganzen Papillarmuskels gekommen. Eine solche Beobachtung gehört zu den allergrößten Seltenheiten.

Das Herz, bei dem dies merkwürdige Ereignis beobachtet wurde, stammt von einem 62jährigen Herrn, der im November des letzten Jahres bei uns zur Sektion kam (Sekt.-Prot. I225/I92I). Das Herz ist im ganzen leicht dilatiert, insbesondere linker Ventrikel und linker Vorhof. Am großen Segel der Mitralis hängt an den Sehnenfäden ein bohnengroßes Gebilde, das auf den ersten Blick wie ein größerer Thrombus erscheinen könnte, der an einem Sehnenfaden hängt, wie man ähnliches zuweilen bei der auf die Sehnenfäden übergreifenden thrombotischen Endokarditis sehen kann. Aber ein näheres Zusehen läßt sofort erkennen, daß derartiges hier nicht vorliegen kann. Sämtliche Klappen des Herzens sind intakt, von irgend welchen endokarditischen Auflagerungen oder sonstigen Thrombenbildungen ist keine Rede. Zudem

1) Literatur hierüber siehe bei L. HEIDENHAIN, Uber die Entstehung von organischen Herzfehlern durch Quetschung. Dtsch. Zeitschr. f. Chirurg. 41. - KULLBS, Experimentelle Untersuchungen über Herz und Trauma. Mitt. a. d. Grenzgeb. d, Med. u. Chirurg. 19. - G. B. GRUBER, Fliegerverletzungen. Kriegspathologische Tagung Berlin, April Igr6, S. 34. - BERBLINGER, Ruptur der Brustorgane infolge stumpfer Gewalteinwirkung. Vierteljahrsschr. f. gerichtl. Med. u. öff. Sanitätsw. 3. Folge, stumpfer Gewalteinwirkung. Vierteljahrsschr. f. gerichtl. Med. u. off. Sanitatsw. 3. Folge,
52, H. 2. IgI6. - MEYER, Traumatische Aortenklappenzerreißung. Med. Klinik, S. 525. 1920. - KENNEWEG, Traumatische Herzklappenruptur. Virchows Arch.f. pathol. Anat. u. Physiol. 232, S. 440. 1921. (Lit.)

2) JAFFE, Sprengung des linken Ventrikels durch Pufferverletzung. Münch. med. Wochenschr., Nr. 23. Igr\%.

2) DUNBAR, Mitralinsuffizienz durch Abreißen dreier Sehnenfäden bei Endokarditis. Dtsch. Arch. f. klin. Med. 49, S. 27 I. I 892 .

4) O. FRAENTZEI, Die Krankheiten des Herzens. 2, 75. $189 \mathbf{r}$ ist die Oberfläche des Anhängsels an den meisten Stellen ganz. glatt wie Endokard. Vor allem aber hängt dieses merkwürdige Gebilde, wie die Abbildung zeigt, nicht an gewöhnlichen Sehnenfäden, sondern an 2 eigenartigen, dicken, gedrehten Strängen, die, wenn man eine schwache Lupe zu Hilfe nimmt, eine verblüffende Ähnlichkeit mit einer Nabelschnur haben. Wir haben dieses eigenartige Bild bei einer Vergrößerung von 2: I in Abb. I zur Darstellung gebracht (nachdem durch einen flachen Rasiermesserschnitt der vorderste Teil des Anhängsels zur mikroskopischen Untersuchung abgeschnitten war).

Auf Grund dieses ganzen. Befundes stellte ich die Diagnose, daß von dem dreikegeligen hinteren Papillarmuskel des linken Ventrikels der eine Kegel vollständig an seiner Basis abgerissen sei. Die mikroskpische Untersuchung bestätigte die Diagnose: Das ganze Gebilde besteht aus völlig nekkrotischer Herzmuskulatur, die häufig noch die Konturen der Fasern und der ganzen Muskelanordnung, aber nirgends mehr irgend welche Kerne erkennen läßt. Stellenweise ist auch die nekrotische Muskulatur zu einer völlig strukturlosen feinkörnigen oder homogenen Masse geworden. Nur im Rande des ganzen Gebildes sehen wir, daß das bindegewebige Endokard mit seinen Zellen in schmaler Zone noch erhalten ist, ja stellenweise finden sich hier ganz schmale atrophische, noch kernhaltige Muskelfasern dicht unter dem Endocard. Die unmittelbar dem Blute anliegende Schicht hat also hier noch genügend Sauerstoff und Ernährung erhalten, um am Leben bleiben $z u$ können.

Die nekrotischen Muskelfasern zeigen fleckweise staubförmige Kalkeinlagerungen. Hier sind vielfach die Muskelfasern - wohl infolge der Verkalkung - in ihren Konturen am besten erhalten. Die verkalkten Teile sind übrigens auch makroskopisch, wie.Abb. I zeigt, als weiße Fleckchen zu sehen. Hier fühlt sich auch der nekrotische Papillarmuskel rauh an.

Sehr interessant mußte nun das Verhalten der nekrotischen Muskulatur an der Basis des Papillarmuskels sein. Merkwürdigerweise ragt hier die Nekrose, von Bindegewebe oder Endothel völlig unbedeckt, unmittelbar in das Blut des linken Ventrikels. Trotz Anfertigung und Untersuchung vieler Schnitte habe ich nirgends auf dieser nekrotischen, hier meist ganz amorphen Masse auch nur die Andeutung eines Thrombus entdecken können. Auch in diesem Teile des Randes finden sich vereinzelte erhaltene atrophische Muskelzellen mit unregelmäßigem Kern, aber nur höchst selten ist hier einmal ein Leukocyt nachzuweisen. Im Augenblick des Abreißens war also offenbar noch nicht in der ganzen RiBlinie die gesamte Muskulatur nekrotisch geworden. Einzelne Muskelfasern waren noch erhalten und sind dann infolge der direkten Berührung mit dem Blutstrom auch noch weiter dem allgemeinen Untergang entgangen.

Es waren nur noch zwei Fragen zu beantworten: $x$. Wie verhält sich die andere Seite der Rißfläche dieses Papillarmuskels?. Warum läßt sich zunächst die Stelle, wo der ganze Muskelkegel herausgerissen ist, durch ihre abnorme und unregelmäßige Beschaffenheit nicht ohne weiteres erkennen. Die Stelle, wo der Papillarmuskel angesessen hat, läBt sich ja ohne weiteres nach dem normalen Bau rekonstruieren. Man sieht hier (siehe die Abbildung) eine flache Mulde, die aber ziemlich glatt und leicht ausgehöhlt ist. Nur eine geringe flache, leicht unebene weißliche Verdickung des Endokards weist an dieser Stelle auf eine kleine Unregelmäßigkeit hin. Hier muß der nekrotische Papillarmuskel herausgerissen sein, aber es ist auch hier nirgends zu einer Thrombenbildung gekommen und von den Seiten ist dann das Endokard über die Rißstelle herübergewachsen und hat dieselbe ausgekleidet. Daher die geringe weißliche Verdickung. Die Stelle selbst habe ich nicht direkt histologisch untersucht, da ich das wertvolle makroskopische Präparat nicht zerstören wollte und da es mir auch für die Beurteilung des ganzen Falles nicht so wesentlich erschien. Zudem dürfte an der Deutung kein Zweifel möglich sein.

Die zweite Frage lautet: Wie ist die so merkwürdige nabelschnurförmige Drehung der beiden Anhängebänder zu erklären? Eine nähere Betrachtung der Verhältnisse in der etwas vergrößerten $\mathrm{Abb}$. I gibt uns, wie ich glaube, ohne weiteres die Erklärung.

Ich bemerke, da $\beta$ die Zeichnung angefertigt wurde, nachdem der abgerissene Papillarmuskel leicht heruntergezogen und mit einer Nadel fixiert war. 